\title{
A Decision-Making Model for Deterring Food Vendors from Selling Harmless Low-Quality Foods as High-Quality Foods to Consumers
}

\author{
Po-Yu Chen \\ Department of Advertising and Strategic Marketing, Ming Chuan University, No. 250 Zhong Shan N. Rd., Sec. 5, Taipei, Taiwan \\ Correspondence should be addressed to Po-Yu Chen; chenboy@mail.mcu.edu.tw
}

Received 3 November 2016; Accepted 29 December 2016; Published 31 January 2017

Academic Editor: Latiful Bari

Copyright @ 2017 Po-Yu Chen. This is an open access article distributed under the Creative Commons Attribution License, which permits unrestricted use, distribution, and reproduction in any medium, provided the original work is properly cited.

For certain types of foods, food vendors often label low-quality foods that are harmless to human health as foods of excellent quality and sell these falsely labeled products to consumers. Because this type of food poses no harm to human health, when public health units discover their act of false labeling or food adulteration, vendors are only penalized with a fine rather than having them assume criminal liability. Upon discovering vendors act of falsely labeling food, public health units typically punish the involved parties according to the extent of false labeling. Such static protective measure is ineffective. Instead, the extent of punishment should be based not only on the extent of false labeling, but also on the frequency of food sampling as well as the number of samples obtained for food inspections. Only through this dynamic approach can food adulteration or false labeling be effectively prevented. Adopting the standpoint of the public sector in food safety management, this study developed a mathematical model that facilitates discussion on the aforementioned problems. Furthermore, we discussed how the supply-demand environmental factors of the food market are influenced by the administrative means that the public health units have used to prevent food false labeling.

\section{Introduction}

Presently, consumers are paying increasing attention to the quality and safety of food products, with particular focus on the direct or potential negative impact of food products manufactured in the biotechnological industry (e.g., genetically modified foods). Food safety is defined in both broad and narrow senses [1]. In the narrow sense, food does not cause any acute, subacute, or chronic hazards to human health. In the broad sense, food products must be assured of their quality, should not be involved in false labeling, adulteration, and counterfeiting, and must conform to relevant health standards. Furthermore, because of advancements in information technology, consumers are exposed to food safety scandals almost every week from newspapers and online sources. These scandals usually involve food safety, quality, and labeling problems causing food products in the market to be recalled or taken off the shelf. Consequently, government health departments worldwide are now forced to pay heightened attention to food quality and safety problems. Henson and Traill [2] indicated that government units across the world have shown a definitive attitude toward the intervention and involvement of food quality and safety management.

In the past 20 years, public health sectors and private organizations worldwide have been developing regulations for food safety management [3], while economically advanced countries are endeavoring to enhance the traceability and transparency of food manufacturing processes [4]. A review of past studies on food safety management reveals that studies have overly focused on discussing safety management systems and strategies. In addition, the discussed contents differ according to the extent of government involvement in food safety and health management [3, 5-7]. Nevertheless, governments around the world have reinforced their food safety standards and management regulations, paying particular emphasis on not only the vertical and horizontal relationships in the supply chain of the food manufacturing industry, but also the division of labor and integration of supply chains in the food industry [8]. Thus, supply 
chain actors (including retailers, wholesalers, manufacturers, suppliers, and logistics providers) are also the driving force for food safety.

Businesses must sustain increased marginal cost of production in order to ensure that their products conform to food safety and management standards; such cost increase suppresses business profits. However, if businesses do not comply with food safety regulations, they must assume the risk of having their reputation being discredited, which also curbs business profits. Therefore, to address this problem, businesses must determine how a balance between "business profit" and "food quality and safety" can be maintained. Accordingly, many scholars have concentrated on assessing the value of willing-to-pay (WTP). Subsequently, they evaluated business profit levels by measuring the effect of WTP on the cognition of consumers regarding food quality and safety.

Hedonic pricing methods [9-13] and mixed multinomial logit approaches [14-16] are typically employed to estimate WTP given that market trading information is accessible. If such information is inaccessible or nonexistent and quality and safety are assumed as capable of increasing WTP, then various other evaluation methods are used such as contingent valuation [17-20], experimental economics [21-23], and conjoint analysis [24-26]. The aforementioned studies have yielded informative results, providing effective and applicable methods for helping businesses strike a balance between "business profit" and "food quality and safety".

Despite that numerous methods have been proposed for food safety management, the reality is the following question: have food quality and safety problems been effectively controlled and improved? The answer to this question is evident from the incessant occurrence of food safety scandals involving adulterated foods and low-quality foods. First, consumers usually purchase products on the basis of "value for money" or "lowest price." In general, businesses believe that price is the most crucial parameter affecting consumers' selection of food products [8]. Second, habitual purchasing behavior is often observed when consumers purchase food products; therefore, consumers' perception of food quality, safety, and price is affected by their prior experience in purchasing the product. Consumers who demonstrate habitual purchasing have a low sensitivity toward the relationship that food quality and safety have with food price. Moreover, they also process information unconsciously [27, 28]. Third, businesses must exert additional marketing efforts to ensure that consumers know that new, quality and safety-improved products are launched. In addition, they must consider consumers' perception of the compensatory relationship between "quality and safety" and "price." Generally, low-quality products are compensated by selling them at a lower price; however, the reason for such compensation might differ according to food types [29]. Nonetheless, these considerations inevitably increase businesses' production cost. Fourth, businesses have a low level of awareness on the consequences of violating food safety regulations. Furthermore, regardless of business size, the status of a business's competitive advantage, and the food safety challenges they face, all of these factors exert no influence on compliance with food safety regulations [3]. Based on the aforementioned discussion, we found that implementing food safety control and management from policy perspectives (e.g., food safety standards) and market perspectives (i.e., consumers' food safety evaluations) is clearly ineffective and inadequate.

When producers of harmless foods are discovered by the public health unit as being involved in broadly defined food safety problems (e.g., false labeling or food adulteration), these food vendors are only penalized with a fine rather than having them assume criminal liability for incurring risk of injury to others and destroy the food products that have not yet been sold in the market. Consequently, falsely labeled (or adulterated) harmless foods are prevalent in the market. This can be attributed to the lack of a mathematical model for analyzing problems concerning food vendors falsely labeling (or adulterating) food products to gain improper profits. This mathematical model can serve as a valuable reference for establishing a penalty function, which can facilitate determining how penalties should differ according to the extent of food false labeling.

This type of food safety management practice is most commonly associated with the following problem: the actual ingredients of a food product do not accord with those labeled on the product packaging. False labeling misleads consumers into thinking that a product has excellent value for money and, therefore, making them willing to purchase it at a high price. In particular, food vendors tend to deceive consumers by selling low-quality products as excellent-quality products. For example, some vendors adulterate a fixed proportion of cooking oil into olive oil and label such adulterated oil as containing pure olive oil. Other vendors have sold Vietnamese rice (or tea) as Taiwan-produced rice (or tea). The act of deceiving consumers by selling low-quality foods as top-quality foods is prevalent for the following reasons:

(1) Foods adulterated with those that are similar in property cannot be easily distinguished with the naked eye, particularly foods that are illegally adulterated with a low quantity of other types of foods.

(2) Because low-quality foods are harmless to human health, food vendors illegally labeling low-quality foods as top-quality foods only face charges of fraud rather than being charged with assault.

(3) Imposing severe punishment on illegal conduct can inevitably deter the occurrence of food vendors selling low-quality foods as high-quality foods. However, when determining the extent of punishment, there is a specific procedure in legal proceedings, and principles of proportionality must be considered instead of allowing the government to independently determine it.

(4) If the penalty amount increases according to the proportion of illegal adulteration by food vendors, then the proportion of adulteration that is selected by food vendors for maximizing profit and is permissible under government standards (including the frequency of adulteration in the inspected food and the number of samples per inspection) will approach a constant. If this constant is greater than 0 , then 
competitor vendors will compete in imitating the food products, thereby causing the prevalence of food false labeling.

This study adopted the government perspective (specifically the health sector), incorporating the aforementioned food safety problems into a mathematical model for discussion. Subsequently, the optimal solution of the mathematical model was derived. We then conducted a sensitivity analysis of how the derived optimal solution is affected by market parameters and government administrative parameters, and the obtained results served as the main findings of this study.

\section{Symbols}

$\theta$ : food vendors deceive consumers by selling lowquality products with a ratio of $\theta$ as top-quality products, where $\theta$ is the vendor's decision variables and $0 \leq \theta \leq 1$. This means that consumers mistakenly think that ingredients are all $100 \%$ quality product, but they are, in fact, only $(1-\theta)$ ratio quality product.

$c_{\theta}$ : is purchase cost per unit food product corresponding to $\theta ; c_{0}$ denotes the purchase cost per unit of top-quality product; $c_{1}$ denotes the purchase cost per unit of low-quality product; and $c_{0}>c_{1} \cdot c_{\theta}$ can be expressed as follows.

$$
c_{\theta}=(1-\theta) c_{0}+\theta c_{1} .
$$

$p$ : is market price per unit of top-quality food.

$l$ : is food expiration date (the maximum period during which the food is edible or valid).

$A$ : is setup cost for vendors to purchase or produce the product.

$h_{\theta}$ : is unit time inventory cost per unit of food corresponding to $\theta ; h_{0}$ denotes the unit time inventory cost per unit of top-quality product; $h_{1}$ represents the unit time inventory cost per unit of low-quality product, where $h_{0}>h_{1} . h_{\theta}$ can be expressed as follows.

$$
h_{\theta}=(1-\theta) h_{0}+\theta h_{1} \text {. }
$$

$M$ : is number of vendors selling the same type of food in the market.

$S$ : is number of vendors from which food products were randomly sampled by the government (health unit).

$g(\theta)$ : is the penalty amount based on $\theta$ degree of false labeling by food vendors randomly sampled by the government, where

$$
\begin{gathered}
g(0)=0, \\
g^{\prime}(0) \geq 0, \\
g^{\prime \prime}(0) \geq 0,
\end{gathered}
$$

$\forall \theta \in[0,1]$.
In the present study, functions conforming to the properties of (3) are referred to as penalty functions conforming to the principle of fair proportionality. Because the government cannot comprehensively determine the amount of food products that have been manufactured but have not yet been sold (unless the vendor is willing to confess the truth), the government calculates the penalty for vendors' dishonest behavior by using the frequency vendors that were discovered as being dishonest (as opposed to using the amount of falsely labeled food products).

This study assumed that the government randomly samples $S$ vendors on average every $L$ time period to inspect their food ingredients.

$L:$ is The time interval at which the government randomly samples food vendors to inspect their food products.

Given $L$ and $S$, the average time interval at which vendors associated with $\theta$ degree of food false labeling were inspected by the government as being involved in false labeling is expressed as follows.

$$
\begin{aligned}
& \frac{S}{M} \cdot L+\frac{M-S}{M} \cdot \frac{S}{M} \cdot 2 L+\cdots+\left(\frac{M-S}{M}\right)^{i-1} \cdot \frac{S}{M} \cdot i L \\
& +\cdots=\left.\frac{S L}{M} \frac{d}{d z}\left(\sum_{i=0}^{\infty} z^{i}\right)\right|_{z=(M-S) / M} \\
& =\left.\frac{S L}{M}\left(\frac{d}{d z} \frac{1}{1-z}\right)\right|_{z=(M-S) / M}=\left.\frac{S L}{M}\left(\frac{1}{(1-z)^{2}}\right)\right|_{z=(M-S) / M}=\frac{L M}{S},
\end{aligned}
$$

where $((M-S) / M)^{i-1} \cdot(S / M)$ denotes the probability of food vendors being discovered as involving in false labeling on the $i$ the government inspection. Therefore, after vendors select $\theta$ value,

the penalty they must pay the government per unit time is

$$
\frac{g(\theta)}{L M / S} \text {. }
$$

$T$ : is vendor inventory cycle.

$x_{\theta}(t)$ : is inventory level at $t$ for food products with health hazard indicator of $\theta$, where $x_{\theta}(t)$ is a decreasing function of $t$ within $[0, T]$ inventory cycle.

$-x_{\theta}^{\prime}(t)$ : is food sales rate at $t$ corresponding to food products sold at price $p$.

$Q_{\theta}(t)$ : is (accumulated) sales volume within $[0, t]$ for food products with health hazard indicator of $\theta$.

$G_{\theta}(T)$ : is profit per unit time corresponding to vendor's decision variable $\theta$ and inventory cycle $T$.

$D(p)$ : is potential demand per unit time reflected by consumer perception of price $p$. In other words, 
it denotes the rate of demand as expressed by consumers without considering food expiration date. Assuming that $D(p)=a-b p$, where $a>0$ represents the maximum potential demand, $-b<0$ denotes the slope of the demand function, and $a / b$ denotes the maximum price $p$.

$\gamma(t)$ : is the amount of food products purchased by consumers according to their daily demand, which is based on the sales price $p$ and $(l-t)$ time remaining before expiration. In other words, it is the ratio of purchase amount of food product with expiration date $l$ to food product with $(l-t)$ remaining before expiration. Specifically, $\gamma(t)$ is a decreasing function of $t$, where $\gamma(0)=1$ and $\gamma(l)=0$.

Considering the transaction cost, consumers adjust their purchase volume according to the ratio of purchase amount of food product with expiration date $l$ to food product with $(l-t)$ remaining before expiration. When consumers purchase a product, the price they pay includes not only the product itself, but also the transaction costs (i.e., purchase time and delivery costs). Therefore, the larger the purchase volume, the smaller the transaction cost per unit of product.

Assuming that $\gamma(t)$ is the linear function of $t$, then the aforementioned properties can be expressed as follows.

$$
\gamma(t)= \begin{cases}\frac{l-t}{l}, & \text { if } t \in[0, l] \\ 0, & \text { if } t \geq l .\end{cases}
$$

Assuming that the food vendors pursue maximizing profit, the profit $p-(c+h T)$ per unit of food sold at $T$ (end of inventory cycle) must be $\geq 0$ (if $p-(c+h T)<0$, then vendors can raise their profit by reducing the initial purchase volume to reduce the sales cycle $T$ ). Thus,

$$
\begin{array}{r}
T \leq l, \\
p-(c+h T) \geq 0 .
\end{array}
$$

From (6), given any $\theta$ value, the following can be obtained:

$$
\begin{aligned}
-x_{\theta}^{\prime}(t)=D(p) \cdot \gamma(t)=(a-b p) \frac{l-t}{l}, & \\
& t \in[0, T] \subseteq[0, l] .
\end{aligned}
$$

Integrating (8),

$$
\begin{aligned}
x_{\theta}(t) & =x_{\theta}(0)+\int_{0}^{t} x_{\theta}^{\prime}(z) d z \\
& =x_{\theta}(0)-\left[(a-b p)\left(t-\frac{t^{2}}{2 l}\right)\right], \quad t \in[0, T],
\end{aligned}
$$

where inventory cycle $T$ satisfies

$$
0=x_{\theta}(T)=x_{\theta}(0)-\left[(a-b p)\left(T-\frac{T^{2}}{2 l}\right)\right] \text {. }
$$

From (10), when $T$ value is determined by vendor, then $x_{\theta}(0)$ can be obtained, thus, simultaneously deriving the function $x_{\theta}(t)$ of (9).

\section{The Mathematical Model for Optimal Inventory Cycle after Vendors Defined $\theta$}

From (8), given $\theta$ value, the sales volume $Q_{\theta}(t)$ within $[0, t]$ is expressed as follows.

$$
\begin{array}{r}
Q_{\theta}(t)=\int_{0}^{t}(a-b p) \frac{l-z}{l} d z=\frac{(a-b p)}{l}\left(l t-\frac{t^{2}}{2}\right) \\
t \in[0, T] .
\end{array}
$$

Furthermore, the inventory level (i.e., sales volume within $[t, T])$ at $t$ during inventory cycle $[0, T]$ is $\int_{t}^{T}(a-b p)((l-$ $z) / l) d z$. Therefore, after vendors decide $\theta$, without considering the loss resulting from the government's penalty, then the sales profit within $[0, T]$ is

$$
\begin{aligned}
& \left(p-c_{\theta}\right) \int_{0}^{T}(a-b p) \frac{l-t}{l} d t-A \\
& -h_{\theta} \int_{0}^{T} \int_{t}^{T}(a-b p) \frac{l-z}{l} d z d t .
\end{aligned}
$$

Using partial integration, $\int_{0}^{T} \int_{t}^{T}(l-z) d z d t$ can be written as $\int_{0}^{T}(l-t) t d t$. Thus, (12) can be rewritten as

$$
\frac{(a-b p)}{l} \int_{0}^{T}(l-t)\left(p-c_{\theta}-h_{\theta} t\right) d t-A .
$$

Using (5) and (13), the following model can be obtained: after vendors define $\theta$, the model for maximum profit $G_{\theta}(T)$ per unit time after determining decision variable $T$ is as follows.

$$
\begin{aligned}
\max _{T} \quad G_{\theta}(T) \\
=\frac{a-b p}{l} \cdot \frac{1}{T} \int_{0}^{T}(l-t)\left(p-c_{\theta}-h_{\theta} t\right) d t-\frac{A}{T} \\
\\
-\frac{g(\theta)}{L M / S}
\end{aligned}
$$

s.t. $\quad T \leq l$,

$T \geq \frac{p-c_{\theta}}{h_{\theta}}$ 


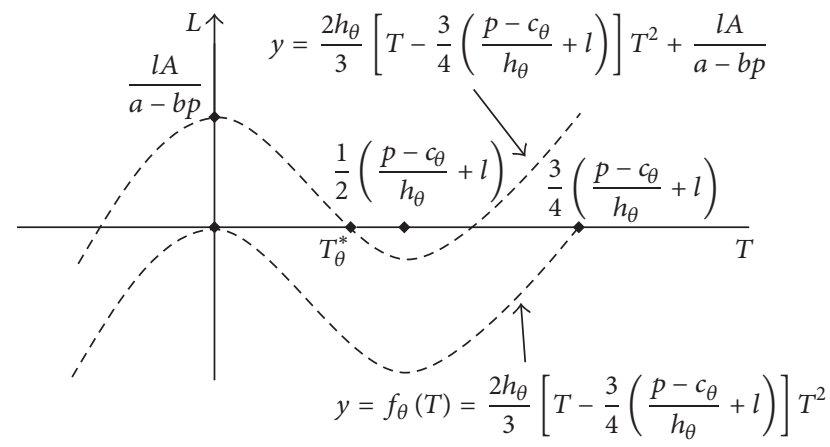

Figure 1: Position of $T_{\theta}^{*}$ for given $\theta$.

\section{The Optimal Inventory Cycle $T_{\theta}^{*}$ in (14) with Given $\theta$}

Differentiating objective function $G_{\theta}$ of $(14)$ with respect to $T$ yields

$$
\begin{aligned}
G_{\theta}^{\prime} & =\frac{a-b p}{l}\left[\frac{(l-T)\left(p-c_{\theta}-h_{\theta} T\right)}{T}\right. \\
& \left.-\frac{\int_{0}^{T}(l-t)\left(p-c_{\theta}-h_{\theta} t\right) d t}{T^{2}}\right]+\frac{A}{T^{2}} \\
& =\frac{a-b p}{l}\left[\frac{(l-T)\left(p-c_{\theta}-h_{\theta} T\right)}{T}\right. \\
& \left.-\left(\frac{l\left(p-c_{\theta}\right)}{T}-\frac{p-c_{\theta}+l h_{\theta}}{2}+\frac{h_{\theta} T}{3}\right)\right]+\frac{A}{T^{2}} \\
& =\frac{a-b p}{l T^{2}}\left[f_{\theta}(T)+\frac{l A}{a-b p}\right],
\end{aligned}
$$

where,

$$
f_{\theta}(T)=\left[\frac{2 h_{\theta}}{3} T-\frac{p-c_{\theta}+l h_{\theta}}{2}\right] T^{2} .
$$

Using (15), we obtain

$$
\begin{aligned}
G_{\theta}^{\prime}(T) & \geq 0 \quad \text { iff } f_{\theta}(T)+\frac{l A}{a-b p} \geq 0 \\
f_{\theta}^{\prime}(T) & =2 h_{\theta} T^{2}-\left(p-c_{\theta}+l h_{\theta}\right) T \\
& =2 h_{\theta}\left[T-\frac{1}{2}\left(\frac{p-c_{\theta}}{h_{\theta}}+l\right)\right] T .
\end{aligned}
$$

Using (7), (15), (16), and (17), the optimal solution $T_{\theta}^{*}$ of (14) can be obtained, as shown in Figure 1.

Proposition 1. Once a vendor decides $\theta$, the inventory cycle $T_{\theta}^{*}$ that maximizes (expected) profit per unit time must satisfy the following:

(i)

$$
\left[\frac{2 h_{\theta}}{3} T_{\theta}^{*}-\frac{p-c_{\theta}+l h_{\theta}}{2}\right] T_{\theta}^{* 2}+\frac{l A}{a-b p}=0 .
$$

(ii) When setup cost $A$ is reduced, or maximum demand a is increased, or demand function slope $-b$ is increased (equivalent to consumers being more sensitive to the price changes in the demand function), the vendors' optimal inventory cycle $T_{\theta}^{*}$ will reduce.

Proof. (i) It can be proven by using (16) and Figure 1.

(ii) From (16), functions $f_{\theta}$ are independent of parameters $A, a$, and $b$; therefore, assumption (ii) yields that $A /(a-$ $b p)$ decreases, and hence the upper curve shifts downward (see Figure 1), reducing its intersection point $T_{\theta}^{*}$ with the horizontal axis.

Proposition 2. $\left(d / d_{\theta}\right) T_{\theta}^{*}<0, \forall \theta \in[0,1]$.

Proof. From (i) and (ii), it can be obtained: when $\theta$ increases, $h_{\theta}$ and $c_{\theta}$ decreased, and $\left(p-c_{\theta}\right) / h_{\theta}$ increases, thus causing the curve $y=\left(2 h_{\theta} / 3\right)\left[T-(3 / 4)\left(\left(p-c_{\theta}\right) / h_{\theta}+l\right)\right] T^{2}+l A /(a-b p)$ to shift downward, reducing $T_{\theta}^{*}$ (see Figure 1 ).

Proposition 3. For some $\theta, \theta \in[0,1]$, the following property is supported:

(i)

$$
\begin{aligned}
& {\left[\frac{1}{2}\left(\frac{p-c_{\theta}}{h_{\theta}}+l\right)-T_{\theta}^{*}\right] \frac{d}{d_{\theta}} T_{\theta}^{*}} \\
& \quad=\frac{h_{1}-h_{0}}{3 h_{\theta}}\left[T_{\theta}^{*}-\frac{3}{4}\left(l-\frac{c_{0}-c_{1}}{h_{0}-h_{1}}\right)\right] T_{\theta}^{*} .
\end{aligned}
$$

$$
T_{\theta}^{*}>\frac{3}{4}\left(l-\frac{c_{1}-c_{0}}{h_{1}-h_{0}}\right) \quad \forall \theta \in[0,1] .
$$

Proof. (i) Differentiating (18) with respect to $\theta$ and using (1) and (2) yields the following:

$$
\begin{gathered}
\frac{2}{3}\left(h_{1}-h_{0}\right) T_{\theta}^{* 3}+2 h_{\theta} T_{\theta}^{* 2} \frac{d T_{\theta}^{*}}{d \theta} \\
-\frac{-\left(c_{1}-c_{0}\right)+l\left(h_{1}-h_{0}\right)}{2} T_{\theta}^{* 2} \\
-\left(p-c_{\theta}+l h_{\theta}\right) T_{\theta}^{*} \frac{d T_{\theta}^{*}}{d \theta}=0 .
\end{gathered}
$$
(19)

Eliminating $T_{\theta}^{*}$ from the aforementioned equation yields

(ii) Using the constraint in (14), a positive value is obtained from the left parenthesis terms in (19); from (2), $\left(h_{1}-h_{0}\right)<0$; and using Proposition 2 and (19) proves (20).

Proposition 4. After the vendors decide $\theta$, the optimal inventory cycle $T_{\theta}^{*}$ corresponding to $\theta$ and the optimal unit time profit 
$G_{\theta}\left(T_{\theta}^{*}\right)$ exhibit the following relationship:

$$
\begin{gathered}
G_{\theta}\left(T_{\theta}^{*}\right)=\frac{a-b p}{l}\left[\left(l-T_{\theta}^{*}\right)\left(p-c_{\theta}-h_{\theta} T_{\theta}^{*}\right)\right. \\
\left.-\frac{l S \cdot g(\theta)}{(a-b p) L M}\right] .
\end{gathered}
$$

Proof. Multiply the left and right terms of (14) by $T$, differentiate them with respect to $T$, and then substitute $T$ with $T_{\theta}^{*}$; subsequently, Proposition 4 can be proven using $d G_{\theta}\left(T_{\theta}^{*}\right) / d T=0$.

\section{Obtaining the Optimal Solution $\theta^{*}$ of $\max _{\theta} G_{\theta}\left(T_{\theta}^{*}\right)$}

Considering the differentiation of (23) with respect to $\theta$ and using (18), the following expression can be obtained:

$$
\begin{aligned}
& \frac{d}{d_{\theta}} G_{\theta}\left(T_{\theta}^{*}\right)=\frac{a-b p}{l}\left[\left(l-T_{\theta}^{*}\right)\right. \\
& \cdot\left(c_{0}-c_{1}+\left(h_{0}-h_{1}\right) T_{\theta}^{*}-h_{\theta} \frac{d T_{\theta}^{*}}{d_{\theta}}\right) \\
& \left.-\left(p-c_{\theta}-h_{\theta} T_{\theta}^{*}\right) \frac{d T_{\theta}^{*}}{d_{\theta}}\right]-\frac{S g^{\prime}(\theta)}{L M} \\
& =\frac{a-b p}{l}\left[\left(2 h_{\theta} T_{\theta}^{*}-l h_{\theta}-p+c_{\theta}\right) \frac{d T_{\theta}^{*}}{d_{\theta}}+l\left(c_{0}-c_{1}\right)\right. \\
& \left.-\left(h_{0}-h_{1}\right) T_{\theta}^{* 2}-\left(c_{0}-c_{1}\right) T_{\theta}^{*}+l\left(h_{0}-h_{1}\right) T_{\theta}^{*}\right] \\
& -\frac{S g^{\prime}(\theta)}{L M}
\end{aligned}
$$

apply (19) to the first term in the middle parenthesis

$$
\begin{aligned}
= & \frac{-(a-b p)\left(h_{0}-h_{1}\right)}{3 l}\left[T_{\theta}^{* 2}-\frac{3}{2}\left(l-\frac{c_{0}-c_{1}}{h_{0}-h_{1}}\right) T_{\theta}^{*}\right. \\
& \left.-\frac{3 l}{h_{0}-h_{1}}\left(c_{0}-c_{1}-\frac{S g^{\prime}(\theta)}{(a-b p) L M}\right)\right] \\
= & \frac{-(a-b p)\left(h_{0}-h_{1}\right)}{3 l}\left[\left(T_{\theta}^{*}-\frac{3}{4}\left(l-\frac{c_{0}-c_{1}}{h_{0}-h_{1}}\right)\right)^{2}-\frac{1}{4}\right. \\
& \left.\cdot \delta_{\theta}\right]
\end{aligned}
$$

where $\delta_{\theta}$ is the discriminant of the $T_{\theta}^{*}$ quadratic polynomial in the middle parenthesis of (24) and is expressed as follows:

$$
\begin{aligned}
\delta_{\theta}= & {\left[\frac{3}{2}\left(l-\frac{c_{0}-c_{1}}{h_{0}-h_{1}}\right)\right]^{2} } \\
& +\frac{12 l}{h_{0}-h_{1}}\left[c_{0}-c_{1}-\frac{S g^{\prime}(\theta)}{(a-b p) L M}\right],
\end{aligned}
$$

$$
\theta \in[0,1]
$$

Differentiating (25) with respect to $\theta$ yields the following:

$$
\begin{aligned}
& \frac{d^{2} G_{\theta}\left(T_{\theta}^{*}\right)}{d \theta^{2}}=\frac{-(a-b p)\left(h_{0}-h_{1}\right)}{3 l}\left[2 \left(T_{\theta}^{*}\right.\right. \\
& \left.-\frac{3}{4}\left(l-\frac{c_{0}-c_{1}}{h_{0}-h_{1}}\right)\right) \frac{d T_{\theta}^{*}}{d \theta}+\frac{3 l}{h_{0}-h_{1}} \\
& \left.\cdot \frac{S g^{\prime \prime}(\theta)}{(a-b p) L M}\right] ; \text { using }(19) \\
& =\frac{-(a-b p)\left(h_{0}-h_{1}\right)}{3 l}\left[2 \left(T_{\theta}^{*}\right.\right. \\
& \left.-\frac{3}{4}\left(l-\frac{c_{0}-c_{1}}{h_{0}-h_{1}}\right)\right)^{2} \\
& \cdot \frac{\left(h_{1}-h_{0}\right) T_{\theta}^{*}}{\left((1 / 2)\left(\left(p-c_{\theta}\right) / h_{\theta}+l\right)-T_{\theta}^{*}\right) 3 h_{\theta}}+\frac{3 l}{h_{0}-h_{1}} \\
& \left.\cdot \frac{S g^{\prime \prime}(\theta)}{(a-b p) L M}\right] .
\end{aligned}
$$

Proposition 5. (i) For some $\theta, \theta \in(0,1]$ such that $d G_{\theta}\left(T_{\theta}^{*}\right) / d_{\theta}=0$, then $\delta_{\theta} \geq 0$ and

$$
\begin{aligned}
\frac{d^{2} G_{\theta}\left(T_{\theta}^{*}\right)}{d \theta^{2}}= & \frac{(a-b p)\left(h_{0}-h_{1}\right)^{2}}{3 l} \frac{\delta_{\theta}}{2} \\
& \cdot \frac{T_{\theta}^{*}}{\left((1 / 2)\left(\left(p-c_{\theta}\right) / h_{\theta}+l\right)-T_{\theta}^{*}\right) 3 h_{\theta}} \\
& -\frac{S g^{\prime \prime}(\theta)}{L M} .
\end{aligned}
$$

(ii) In (i), if (27) is negative, then $\theta$ is the maximum point of the function $G_{\theta}\left(T_{\theta}^{*}\right)$; and if (27) is positive, then $\theta$ is the minimum point of the function $G_{\theta}\left(T_{\theta}^{*}\right)$.

Proof. Combining (25) and (26), we obtain (27).

Proposition 6. If $\delta_{0} \leq 0$, then the optimal solution $\theta^{*}$ of $\max G_{\theta}\left(T_{\theta}^{*}\right)$ is $\theta^{*}=0$.

Proof. From (3) and (25), $\delta_{\theta}$ is a decreasing function of $\theta$; if $\delta_{0} \leq 0$, then $\delta_{\theta} \leq 0, \forall \theta \in[0,1]$, thereby obtaining $\left(d / d_{\theta}\right) G_{\theta}\left(T_{\theta}^{*}\right) \leq 0, \forall \theta \in[0,1]$ from $(25)$. Therefore, $\theta^{*}=$ 0 .

Proposition 7. (i) The necessary condition for $\theta^{*}=0$ is $\left[T_{\theta}^{*}-\right.$ $\left.(3 / 4)\left(l-\left(c_{0}-c_{1}\right) /\left(h_{0}-h_{1}\right)\right)\right]^{2} \geq(1 / 4) \delta_{0}$ (i.e., if $\delta_{0} \geq 0$, then $\left.T_{\theta}^{*}-(3 / 4)\left(l-\left(c_{0}-c_{1}\right) /\left(h_{0}-h_{1}\right)\right) \geq(1 / 2) \sqrt{\delta}_{0}\right)($ see $(20))$.

(ii) The necessary condition for $\theta^{*}=1$ is $\left[T_{\theta}^{*}-(3 / 4)\left(l-\left(c_{0}-\right.\right.\right.$ $\left.\left.\left.c_{1}\right) /\left(h_{0}-h_{1}\right)\right)\right]^{2} \leq(1 / 4) \delta_{1}$ (i.e., if $\delta_{1} \geq 0$, then $T_{1}^{*}-(3 / 4)(l-$ $\left.\left.\left(c_{0}-c_{1}\right) /\left(h_{0}-h_{1}\right)\right) \leq(1 / 2) \sqrt{\delta}_{1}\right)$.

(iii) The necessary condition for $\theta^{*} \in(0,1)$ is $\left[T_{\theta}^{*}-(3 / 4)(l-\right.$ $\left.\left.\left(c_{0}-c_{1}\right) /\left(h_{0}-h_{1}\right)\right)\right]^{2}=(1 / 4) \delta_{\theta^{*}}$ (i.e., if $\delta_{\theta^{*}} \geq 0$, then $T_{\theta}^{*}=$ $\left.(3 / 4)\left(l-\left(c_{0}-c_{1}\right) /\left(h_{0}-h_{1}\right)\right)+(1 / 2) \sqrt{\delta}_{\theta^{*}}\right)(\operatorname{see}(20))$. 
Proof. The necessary condition for $\theta^{*}=0$ is $\left(d G_{\theta}\left(T_{\theta}^{*}\right) /\right.$ $\left.d_{\theta}\right)\left.\right|_{\theta^{*}=0} \leq 0$; the necessary condition for $\theta^{*}=1$ is $\left.\left(d G_{\theta}\left(T_{\theta}^{*}\right) / d_{\theta}\right)\right|_{\theta=1} \geq 0$; the necessary condition for $\theta^{*} \in(0,1)$ is $\left.\left(d G_{\theta}\left(T_{\theta}^{*}\right) / d_{\theta}\right)\right|_{\theta=\theta^{*}}=0$. Therefore, Proposition 7 can be proven by (24).

Proposition 8. If $g(\theta)$ is the linear function of $\theta, \theta \in[0,1]$, then $\theta^{*}=0$ or $\theta^{*}=1$.

Proof. The assumption yields that there exists a positive real number satisfying

$$
g(\theta)=e \theta, \quad \forall \theta \in[0,1]
$$

therefore,

$$
g^{\prime \prime}(\theta)=0,
$$

and from (27) it leads to $d^{2} G_{\theta}\left(T_{\theta}^{*}\right) / d \theta^{2} \geq 0, \forall \theta \in[0,1]$. This implies that $g(\theta)$ has no maximum point. Thus, $\theta^{*}=0$ or $\theta^{*}=1$.

Proposition 9. If the unit time adulteration marginal penalty $S g^{\prime}(0) / L M$ at $\theta=0$ is smaller than the price difference $\left(c_{0}-\right.$ $\left.c_{1}\right)(a-b p)$ between the purchase costs of top-quality and lowquality products per unit time demand, then $\theta^{*} \neq 0$.

Proof. The assumption yields that

$$
\frac{S g^{\prime}(0)}{L M} \leq\left(c_{0}-c_{1}\right)(a-b p)
$$

using (25), it leads to

$$
\frac{1}{4} \delta_{0} \geq\left[\frac{3}{4}\left(l-\frac{c_{0}-c_{1}}{h_{0}-h_{1}}\right)\right]^{2} .
$$

Therefore, $\theta^{*} \neq 0$ can be proven using (i) in Proposition 7.

\section{Conclusions}

In this study, we incorporated the food expiration factors that influence consumers' purchase intention and the volume they purchase into the conventional EOQ model, establishing the food EOQ model. Subsequently, based on this food EOQ model, we discussed the food safety problems that have attracted the attention and generated intensive response from people of the Taiwanese society. In practice, many food vendors had been discovered to be involved in false labeling of food products such as olive oil adulterated with different proportions of cooking oil. When the government discovers that a vendor sells harmless low-quality food products as topquality products to consumers, these falsely labeled foods are not destroyed because of their harmless property. Thus, different methods are employed to calculate the inventory risk cost of vendors' food products and that of hazardous food additives. This study developed a mathematical model based on the aforementioned food safety problems. The results revealed the following interesting properties.

Property 1. If the government follows the principle of adopting mild penalty, then regardless of which penalty function $\mathrm{g}$ based on the principle of proportionality the government adopts, vendors will not be prompted to produce or sell food products containing no low-quality ingredients (refer to Proposition 9). This indicates that vendors inevitably falsely label their food products. In addition, the government's administrative means can only reduce the optimal ratio of $\theta^{*}$ in vendors' food products containing low-quality ingredient, rather than reduce $\theta^{*}$ to 0 . This suggests that, in practice, if the labeled food ingredient is $100 \%$ true then it is attributed to the vendor having self-constraint because of his or her morality, instead of to the penalty imposed by the government to deter the act of food false labeling.

Property 2. According to Property 1, if the government adopts an adequately strict penalty of $g^{\prime}(0)$, then such measure might encourage vendors to select an optimal lowquality ingredient ratio of $\theta^{*}=0$. In addition, this study revealed how $g^{\prime}(0)$ must be related to the model parameters in order to encourage vendors to select $\theta^{*}=0$ (refer to Propositions 6 and 7).

Property 3. When the public health department decides the penalty function $g(\theta)$ for vendors who falsely labeled lowquality foods with a ratio of $\theta$ as top-quality foods, and the department's inspection frequency and number of vendor samples per inspection are given, this study provided a mathematical model (refer to Proposition 7) for determining the optimal (illegal) adulteration ratio that maximizes vendors' profit. Under special circumstances, if the penalty function $g(\theta)$ is the linear function of the adulteration ratio $\theta$, then the optimal adulteration ratio $\theta^{*}$ for vendors must be either 0 or 1 (refer to Proposition 8).

\section{Competing Interests}

The author declares that he has no competing interests.

\section{References}

[1] C. Ritson and L. W. Mai, "The economics of food safety," Nutrition \& Food Science, vol. 98, no. 5, pp. 253-259, 1998.

[2] S. Henson and B. Traill, "The demand for food safety: market imperfections and the role of government," Food Policy, vol. 18, no. 2, pp. 152-162, 1993.

[3] L. D. Mensah and D. Julien, "Implementation of food safety management systems in the UK," Food Control, vol. 22, no. 8, pp. 1216-1225, 2011.

[4] E. Hanak, E. Boutrif, and M. Pineiro, "Food safety management in developing countries," in Proceedings of the International Workshop, CIRAD-FAO, pp. 11-13, Montpellier, France, 2000.

[5] S. Henson and J. Caswell, "Food safety regulation: an overview of contemporary issues," Food Policy, vol. 24, no. 6, pp. 589-603, 1999.

[6] M. Garcia Martinez, A. Fearne, J. A. Caswell, and S. Henson, "Co-regulation as a possible model for food safety governance: opportunities for public-private partnerships," Food Policy, vol. 32, no. 3, pp. 299-314, 2007.

[7] F. Wendler, "The public-private regulation of food safety through HACCP: what does it mean for the governance capacity 
of public and private actors?" in European Risk Governance: Its Science, Its Inclusiveness and Its Effectiveness, E. Vos, Ed., pp. 223-256, University of Mannheim, Mannheim, Germany, 2008.

[8] K. G. Grunert, "Food quality and safety: consumer perception and demand," European Review of Agricultural Economics, vol. 32, no. 3, pp. 369-391, 2005.

[9] B. E. Steiner, "Australian wines in the British wine market: a hedonic price analysis," Agribusiness, vol. 20, no. 3, pp. 287-307, 2004.

[10] R. Scarpa, M. Thiene, and L. Galletto, "Consumers wtp for wine with certified origin: preliminary results from latent classes based on attitudinal responses," Journal of Food Products Marketing, vol. 15, no. 3, pp. 231-248, 2009.

[11] E. Brentari, R. Levaggi, and P. Zuccolotto, "Pricing strategies for Italian red wine," Food Quality and Preference, vol. 22, no. 8, pp. 725-732, 2011.

[12] S. Szathvary and S. Trestini, "A hedonic analysis of nutrition and health claims on fruit beverage products," Journal of Agricultural Economics, vol. 65, no. 2, pp. 505-517, 2014.

[13] E. Brentari, R. Levaggi, and P. Zuccolotto, "A hedonic price analysis for the Italian wine in the domestic market," Quality and Quantity, vol. 49, no. 3, pp. 999-1012, 2015.

[14] C. Bonnet and M. Simioni, "Assessing consumer response to protected designation of origin labelling: a mixed multinomial logit approach," European Review of Agricultural Economics, vol. 28, no. 4, pp. 433-449, 2001.

[15] U. Enneking, "Willingness-to-pay for safety improvements in the German meat sector: the case of the Q\&S label," European Review of Agricultural Economics, vol. 31, no. 2, pp. 205-223, 2004.

[16] Z. Pieniak, W. Verbeke, F. Vanhonacker, L. Guerrero, and M. Hersleth, "Association between traditional food consumption and motives for food choice in six European countries," Appetite, vol. 53, no. 1, pp. 101-108, 2009.

[17] S. Boccaletti and M. Nardella, "Consumer willingness to pay for pesticide-free fresh fruit and vegetables in Italy," International Food and Agribusiness Management Review, vol. 3, no. 3, pp. 297-310, 2000.

[18] A. Maruyama and M. Kikuchi, "Risk-learning process in forming willingness-to-pay for egg safety," Agribusiness, vol. 20, no. 2, pp. 167-179, 2004.

[19] A. Tarkiainen and S. Sundqvist, "Subjective norms, attitudes and intentions of Finnish consumers in buying organic food," British Food Journal, vol. 107, no. 11, pp. 808-822, 2005.

[20] A. Botonaki, K. Polymeros, E. Tsakiridou, and K. Mattas, "The role of food quality certification on consumers' food choices," British Food Journal, vol. 108, no. 2, pp. 77-90, 2006.

[21] J. L. Lusk, J. A. Fox, T. C. Schroeder, J. Mintert, and M. Koohmaraie, "In-store valuation of steak tenderness," American Journal of Agricultural Economics, vol. 83, no. 3, pp. 539-550, 2001.

[22] J. L. Lusk, L. O. House, C. Valli et al., "Effect of information about benefits of biotechnology on consumer acceptance of genetically modified food: evidence from experimental auctions in the United States, England, and France," European Review of Agricultural Economics, vol. 31, no. 2, pp. 179-204, 2004.

[23] M. L. Loureiro and W. J. Umberger, "A choice experiment model for beef: what US consumer responses tell us about relative preferences for food safety, country-of-origin labeling and traceability," Food Policy, vol. 32, no. 4, pp. 496-514, 2007.
[24] T. Bech-Larsen and K. G. Grunert, "The perceived healthiness of functional foods: a conjoint study of Danish, Finnish and American consumers' perception of functional foods," Appetite, vol. 40, no. 1, pp. 9-14, 2003.

[25] K. G. Grunert, T. Bech-Larsen, L. Lähteenmäki, Ø. Ueland, and A. Åström, "Attitudes towards the use of GMOs in food production and their impact on buying intention: the role of positive sensory experience," Agribusiness, vol. 20, no. 1, pp. 95107, 2004.

[26] I. Siró, E. Kápolna, B. Kápolna, and A. Lugasi, "Functional food. Product development, marketing and consumer acceptance-a review," Appetite, vol. 51, no. 3, pp. 456-467, 2008.

[27] R. Adaval and K. B. Monroe, "Automatic construction and use of contextual information for product and price evaluations," Journal of Consumer Research, vol. 28, no. 4, pp. 572-588, 2002.

[28] R. Adaval and R. S. Wyer Jr., "Conscious and nonconscious comparisons with price anchors: effects on willingness to pay for related and unrelated products," Journal of Marketing Research, vol. 48, no. 2, pp. 355-365, 2011.

[29] J. R. Bettman, M. F. Luce, and J. W. Payne, "Constructive consumer choice processes," Journal of Consumer Research, vol. 25 , no. 3, pp. $187-217,1998$. 

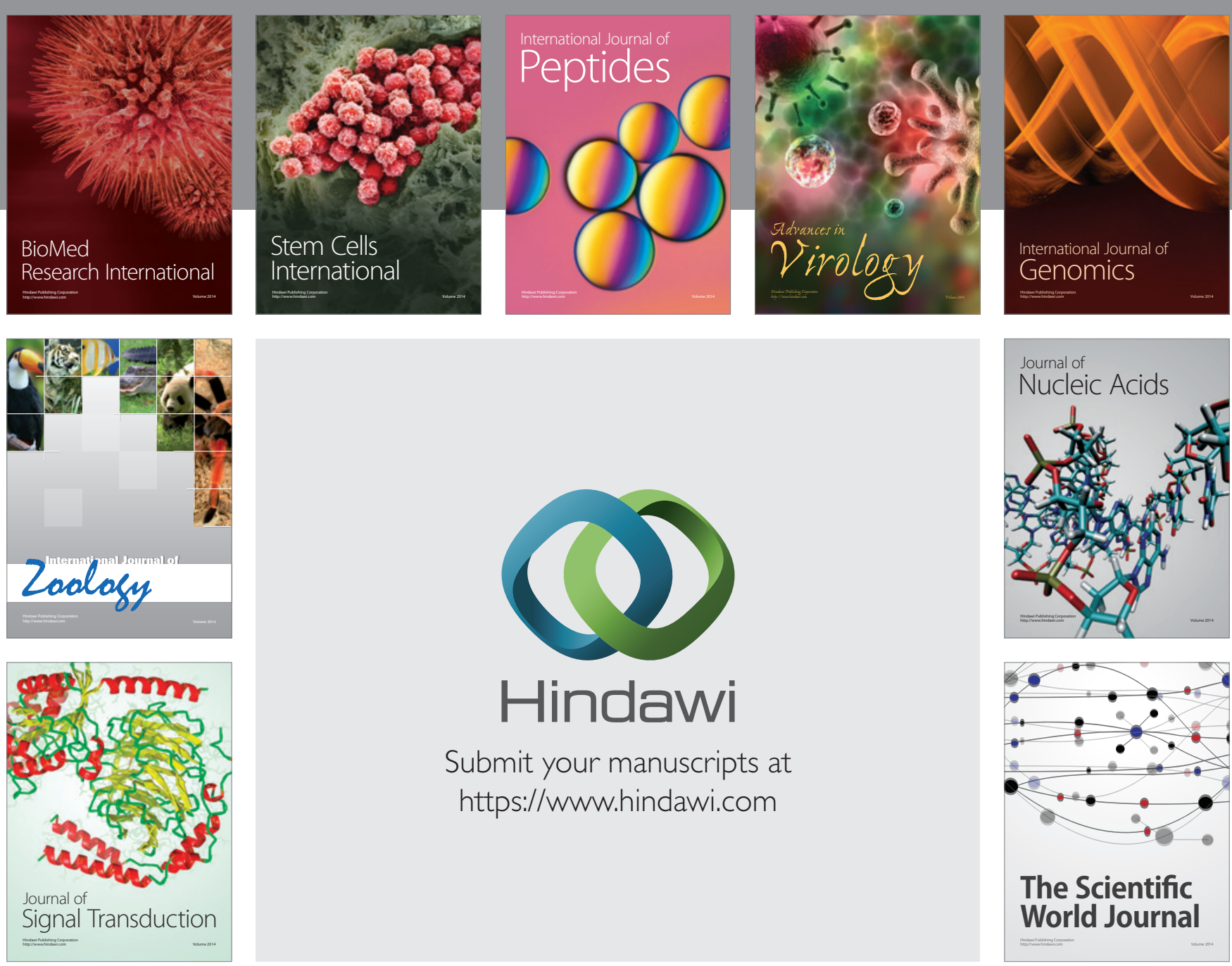

Submit your manuscripts at

https://www.hindawi.com
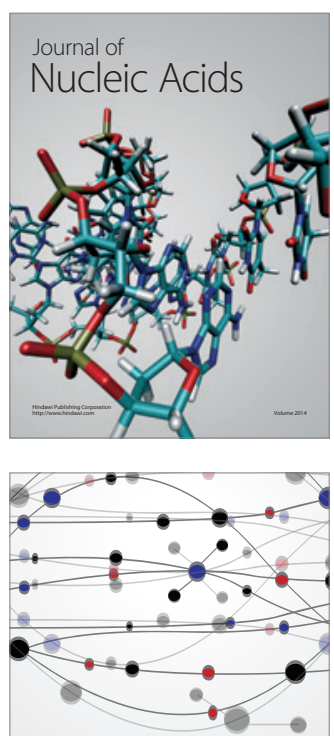

The Scientific World Journal
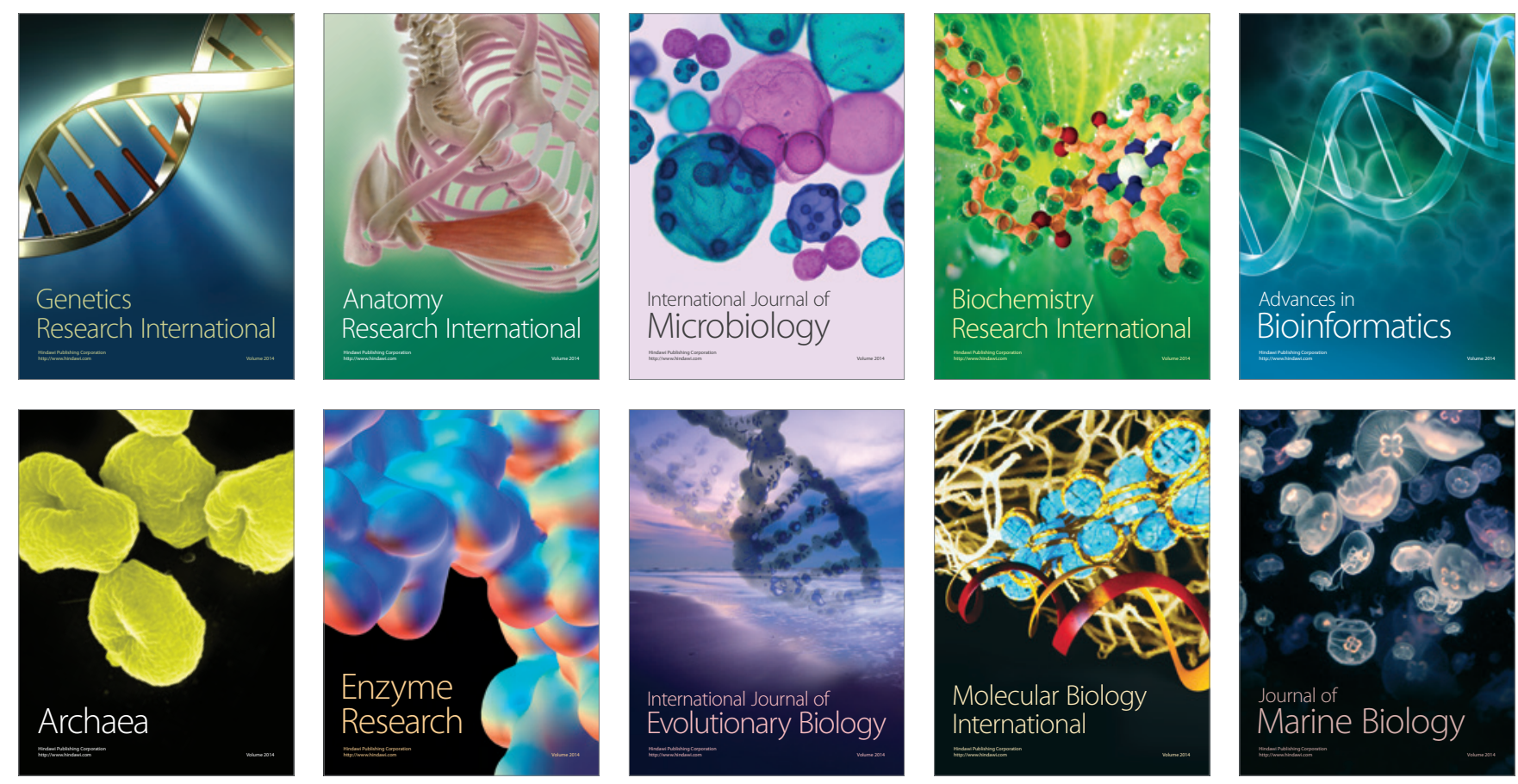